\title{
Computer-Aided Project Duration Forecasting Subjected to the Impact of Rain
}

\author{
S.-J. Guo \\ Department of Civil Engineering, National Taiwan University, Taipei 10617, Taiwan
}

\begin{abstract}
Rain is a significant climate factor for project duration control. This study presents an analytical model for project duration forecasting subjected to the impact of rain. Also developed herein is the concept of "level of rain" to analyze the direct and subsequent productivity losess based on various amounts of precipitation. Based on the analytical model, a computer-aided project duration forecasting system subjected to the impact of rain is developed. The proposed system incorporates historical precipitation records, expert experiences, and fuzzy-set techniques in duration forecasting. Moreover, the proposed system's effectiveness is demonstrated by a highway construction project. The system proposed herein can provide more realistic duration forecasting for project managers while considering the impact of rain.
\end{abstract}

\section{INTRODUCTION}

Conventional scheduling software such as P3, OPENPLAN, and Microsoft Project has been used extensively in schedule planning for various construction projects. However, these software programs do not consider the impact of rain in the scheduling process. If the scheduler does not build in effects of rain in activity duration, then two identical projects with the same network logic and activities would yield the same total project duration even though the weather conditions in the two construction sites are totally different. In other words, these software systems do not account for rain explicitly but depend on the user to deal with this issue implicitly in the activity duration. Moreover, the start date of the construction also should affect the final completion date of the project due to the distribution of rains in a year. For instance, rain can significantly affect the exterior wall finishing in building construction. This activity, if scheduled in the dry season, can be completed in 1 month. However, if the project's starting date is shifted for one season, then the exterior wall finishing can be shifted to the raining season. In this case, it may take at least 2 months to complete the exterior wall finishing. On the other hand, the location of the construction site certainly would yield different raining seasons, resulting in different project completion dates.

In practice, an experienced scheduler should consider and estimate how rain might affect the schedule and total duration. However, consider a situation in which the scheduler is unfamiliar with the distribution of rain at the construction site. Inappropriate estimating of rain's impact could cause the project schedule to significantly differ from the actual duration. An increasing number of construction projects are estimated on a calendar-day basis, in which the completion date already may be specified in the contract. The contractor must prepare a feasible schedule plan to avert an enormous penalty in scheduling delays. This situation becomes more serious if the contractor does not have much relevant working experience with the distribution of rain in a particular city or area. An effective means of averting this problem involves incorporating the historical data of rain in the duration forecasting process. With the historical data of rain, the scheduler can adjust each activity's duration in the network to yield a more feasible completion date. The scheduler can assign an appropriate duration for each activity based on a no-rain condition; meanwhile, the schedule impact of rain is adjusted by the historical data of rain. By employing this approach, the scheduler can more accurately predict the project completion date even though the scheduler does not have much relevant experience with the distribution of rain of the construction site.

\section{LITERATURE REVIEWS}

The impact of rain on project scheduling has received limited attention. In practice, the scheduling uncertainties are usually estimated by experience and judgment. However, the impact of rain and precipitation is not distinguished from other uncertain factors. A lot of investigators such as Crandall, ${ }^{6}$ Moder et al., ${ }^{7}$ Ahuja and Nandakumar, ${ }^{2}$ and Touran and Wiser ${ }^{11}$ used Monte Carlo simulation techniques for handling sched- 
ule uncertainties as well as impact of rain. Benjamin and Greenwald $^{4}$ and Carr ${ }^{5}$ started to consider the effects of weather on construction and proposed the concept of weather sensitivity correction and DECAD (uncertainty dependent of calendar date). Padilla and $\mathrm{Carr}^{9}$ developed weather correction factors for resource strategies of project management. In a related work, a fuzzy-set concept was developed by Ayyub Haldar $^{3}$ to cope with project scheduling and forecasting uncertainties. In addition, Smith and Hancher ${ }^{10}$ developed a fuzzy-set model to evaluate the schedule impact of precipitation. That investigation also applied the fuzzy concept of Ayyub and Monte Carlo simulation technique to predict the future weather pattern and the amount of rain.

Smith's study, although presenting an effective means of estimating the schedule impact of precipitation, has certain limitations. Concerns arise over whether the weather conditions are divided as only rainy and sunny days; that study also does not consider subsequent impact of rain, as well as the appropriateness of using Monte Carlo simulation for predicting weather uncertainties. Adeli and Karim ${ }^{1}$ developed a jobcondition modifier to model productivity loss during and after rainfall. Moselhi et al. ${ }^{8}$ developed a decision support system, named WEATHER, for estimating the combined effect of reduced labor productivity and work stoppage caused by adverse weather conditions on construction sites. The weather data in Canada were build into this system to facilitate the planning and scheduling process. Although Moselhi et al. adapted the historical data of rain to develop their system, the subsequent impact of rain is still neglected in this recent study. To address these concerns, three aspects must be discussed:

1. The amount of rain differs according to the location and date/season. In Monte Carlo simulation, assuming a certain distribution and frequency of rain is inappropriate. Instead, applying historical data of rain toward simulation would be more effective.

2. Different amounts of rain should result in different levels of impact for a schedule delay. Various levels of rain must be defined to evaluate the productivity loss of different activities and the total duration impact. Therefore, a fuzzy-set approach can be developed to convert the amount of rain into different amounts of productivity loss.

3. The subsequent impact of rain cannot be neglected. A heavy one-day rain not only delays the work for that particular day but also may cause several days of productivity loss. Under some circumstances, the subsequent work stoppage may be more serious than the direct impact. However, previous literature did not emphasize this issue.
Table 1

Level of rain and description

\begin{tabular}{lll}
\hline Level of rain & Precipitation & Description \\
\hline Drizzling & $<1 \mathrm{~mm} /$ day & $\begin{array}{l}\text { Drizzle, umbrella may be } \\
\text { unnecessary }\end{array}$ \\
Slight & $1-10 \mathrm{~mm} /$ day & $\begin{array}{l}\text { Ordinary rain; umbrella is } \\
\text { necessary } \\
\text { Rainfall accumulates on the } \\
\text { ground } \\
\text { Pedium }\end{array}$ \\
Heavy & $10-25 \mathrm{~mm} /$ day & cloudburst, storm \\
\hline
\end{tabular}

\section{HISTORICAL DATA ON RAIN}

Historical data for rain distribution and patterns are a prerequisite for developing the schedule forecasting model subjected to the impact of rain and constructing a computeraided scheduling system. These data can be obtained from the Weather Bureau. In Taiwan, the Weather Bureau has made observations and maintained records for rain, temperature, and wind for each county since 1949. Updated records for the rain distribution and patterns in Taiwan have been published, containing the historical daily data for rain for the past three decades. This source document provides preliminary information for this study.

Although Taiwan is not large, each county significantly varies in terms of rain distribution. For instance, north Taiwan experiences about 100 to 180 days of rain annually. However, south Taiwan, has only around 70 to 90 days of rain annually. A rainy day is defined as more than $1 \mathrm{~mm} /$ day of accumulated rain. The Weather Bureau defines five levels of rain according to the amount of accumulated rain, i.e., 1, 10, 25, 50, and $100 \mathrm{~mm}$ and up per day. The latter two typically incur property damage or fatalities.

Generally, $1 \mathrm{~mm} /$ day of rain is referred to as drizzling, possibly interfering with some outdoor activities; $10 \mathrm{~mm}$ /day of rain is referred to as only a slight amount of rain, possibly interfering with most outdoor activities (also, the rainfall may begin accumulating on the ground before it has been distributed); $25 \mathrm{~mm} /$ day of rain is referred to as medium rain, and subsequently, most outdoor activities will cease; and 50 and $100 \mathrm{~mm} /$ day of rain usually comes along with a storm and occurs in mountainous areas. This study refines these definitions for evaluating different impacts of productivity losses as in Table 1.

\section{ANALYTICAL MODEL}

\subsection{Definitions of variables}

Figure 1 defines two major variables to overcome the previous problems: 
Table 2

Example of questionnaire result for $P L$ and $D$

\begin{tabular}{|c|c|c|c|c|c|c|c|c|}
\hline \multirow[b]{2}{*}{ Level of rain } & \multicolumn{2}{|c|}{ Drizzling } & \multicolumn{2}{|c|}{ Slight } & \multicolumn{2}{|c|}{ Medium } & \multicolumn{2}{|c|}{ Heavy } \\
\hline & $P L$ & $D$ & $P L$ & $D$ & $P L$ & $D$ & $P L$ & $D$ \\
\hline Earth backfill & $0 \%$ & 0 & $20 \%$ & 1 & $80 \%$ & 2 & $100 \%$ & 6 \\
\hline
\end{tabular}

1. Productivity loss $(P L)$ : The productivity loss attributed to the impact of rain. In contrast to the no-rain situation, the productivity loss is $0 \%$. A productivity loss of $50 \%$ creates a scenario in which only half the work is completed.

2. Days of subsequent impact $(D)$ : The duration that the productivity is affected, as attributed to the impact of rain. It is counted from the stop of rainfall until the productivity loss is decreased to $0 \%$ (no-rain situation).

\subsection{Productivity impact of a single rainfall}

A questionnaire survey was conducted to collect the productivity losses and days of consequential impacts for various activities subjected to different levels of rain. A typical result is shown in Table 2. The questionnaire was administered to 24 experienced site engineers and supervisors of 12 highway construction projects. The questionnaire results were then reviewed by an expert meeting that consisted of four senior highway construction site supervisors. The expert reviews provide the final result of the survey by combining the variations between individual responses. In reality, the value of $D$ should depend on the size of the activity as well as any postrain remedial action taken. However, this survey neglects these effects and assumes that $D$ is dependent only on the time needed to release the impact of rain without special remedial action. The productivity losses and days of subsequent impacts are used as input variables for the evaluation model. For other construction projects, these data should be revised according to different characteristics and requirements of activities.

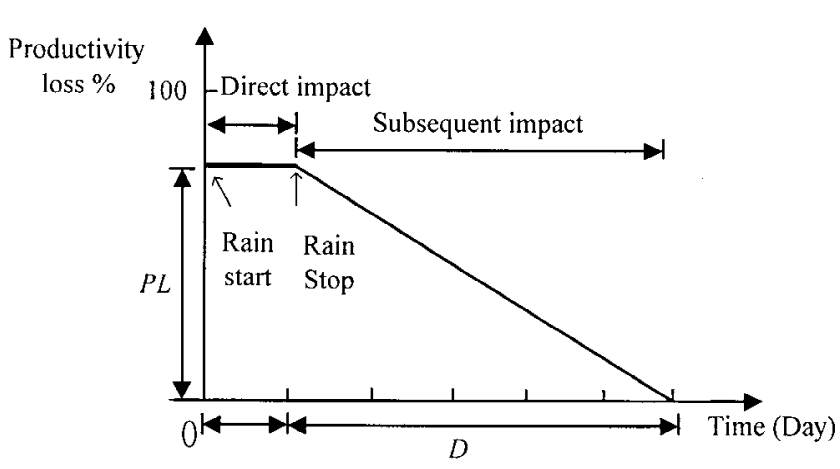

Fig. 1. Productivity loss and days of subsequent impact.

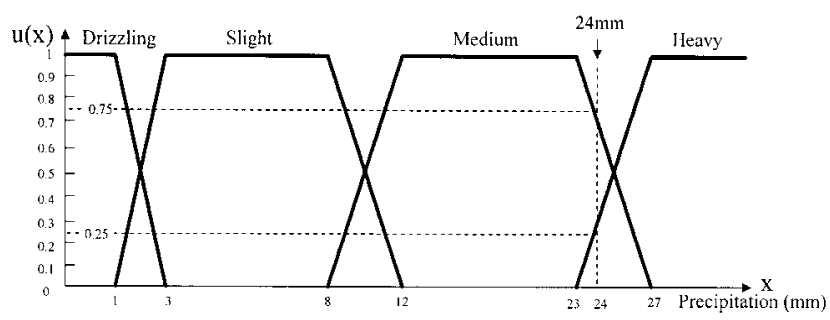

Fig. 2. Fuzzy membership function $u(x)$.

Constructing the evaluation model involves combining the historical daily data of precipitation with the $P L$ and $D$. In addition, the questionnaire is conducted on the basis of different levels of rain instead of the exact amount of precipitation, thereby necessitating that the exact amount of precipitation be converted into a fuzzy description of different levels of rain. To achieve this objective, a well-adopted fuzzy membership function $u(x)$ is used herein. Figure 2 defines $u(x)$, as illustrated below.

As Figure 2 shows, a fuzzy set $R$ of precipitation can be defined as Equation (1). For instance, with a 24-mm amount of precipitation, the fuzzy set $R$ can be obtained as in Equation (2).

$$
\begin{aligned}
& R=\left[u\left(x_{1}\right) / \text { Drizzling, } u\left(x_{2}\right) /\right. \text { Little, } \\
& u\left(x_{3}\right) / \text { Medium, } u\left(x_{4}\right) / \text { Heavy] } \\
& R=[0,0,0.75,0.25]
\end{aligned}
$$

According to the survey results in Table 2, the productivity losses for different levels of rain $(P L)$ can be defined as a $1 \times 4$ matrix. Then the direct productivity loss $L_{D}$ due to a particular amount of precipitation for a specific activity can be calculated as in Equation (3):

$$
L_{D}=R \times P L(\%)
$$

In this example, the direct productivity loss of earth backfill subjected to a 24-mm amount of rain is calculated as in Equation (4):

$$
\begin{aligned}
L_{D} & =R \times P L=[0,0,0.75,0.25] \times\left[\begin{array}{c}
0 \\
20 \% \\
80 \% \\
100 \%
\end{array}\right] \\
& =(0.75 \times 0.8+0.25 \times 1)=85 \%
\end{aligned}
$$

In a similar approach, the days of subsequent impact for different levels of rain $(D)$ can be defined as a $1 \times 4$ matrix. Thus the total days of subsequent impact $D_{s}$ due to a particular amount of precipitation for a specific activity can be calculated as in Equation (5). The case example can be calculated in Equation (6) as a result of 3 days.

$$
D_{s}=R \times D \text { (days) }
$$




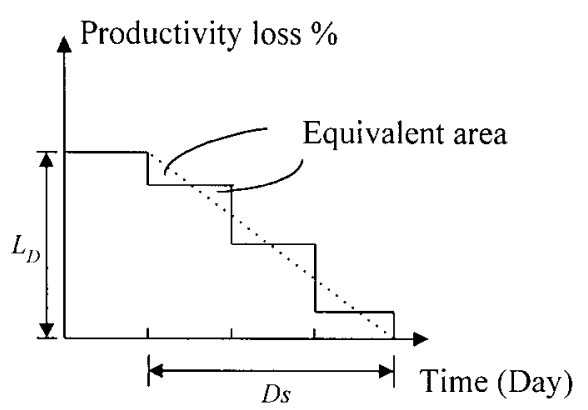

Fig. 3. Subsequent productivity losses attributed to a single rainfall.

$$
\begin{aligned}
D_{s} & =R \times D=[0,0,0.75,0.25] \times\left[\begin{array}{l}
0 \\
1 \\
2 \\
6
\end{array}\right] \\
& =(0.75 \times 2+0.25 \times 6)=3 \text { (days) }
\end{aligned}
$$

According to Equations (4) and (6), the $L_{D}$ and $D_{s}$ for earth backfill subjected to a 24-mm amount of rain are calculated. Then the individual subsequent productivity loss for each of these 3 days, attributed to this 24-mm rainfall, can be evaluated as in Figure 3 and Equation (7).

$$
L_{j}= \begin{cases}L_{D} & j=0 \\ L_{D}\left(2 D_{s}-2 j+1\right) / 2 D_{s} & 0<j \leq D_{s} \\ 0 & j>D_{s}\end{cases}
$$

where $L_{j}$ is the subsequent productivity loss for the following $j$ th day

According to Equation (7), the productivity loss for each day can be obtained as follows:

$$
\begin{aligned}
& L_{0}=85 \% \\
& L_{1}=85 \% \times 5 / 6=71 \% \\
& L_{2}=85 \% \times 3 / 6=43 \% \\
& L_{3}=85 \% \times 1 / 6=14 \%
\end{aligned}
$$

\subsection{Productivity impact of multiple rainfalls}

In practice, multiple rainfalls may occur all the time and result in overlapping impacts on productivity and schedule. For highway construction, this effect is significant because the compacting work cannot be performed until the water in soil has been properly distributed to a certain extent. When multiple rainfalls occur, the impacts of subsequent productivity losses should be accumulated. In this study I adapt an upper limit of productivity loss of $100 \%$ for calculating the overlapping subsequent productivity losses attributed to multiple rainfalls. The total productivity loss of the $i$ th day $\left(L_{i}\right)$ due to multiple rainfalls can be calculated as in Figure 4 and

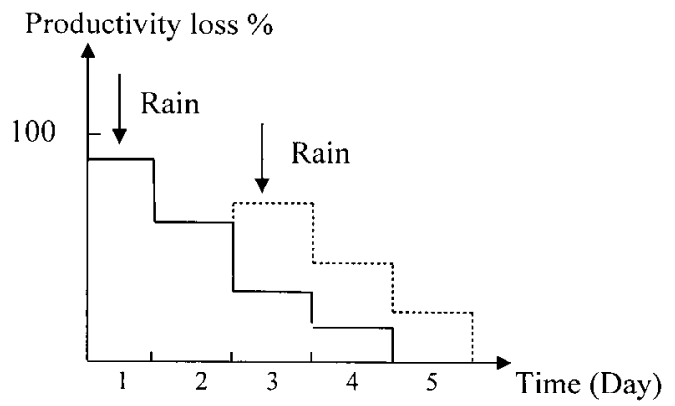

Fig. 4. Productivity losses due to multiple rainfalls.

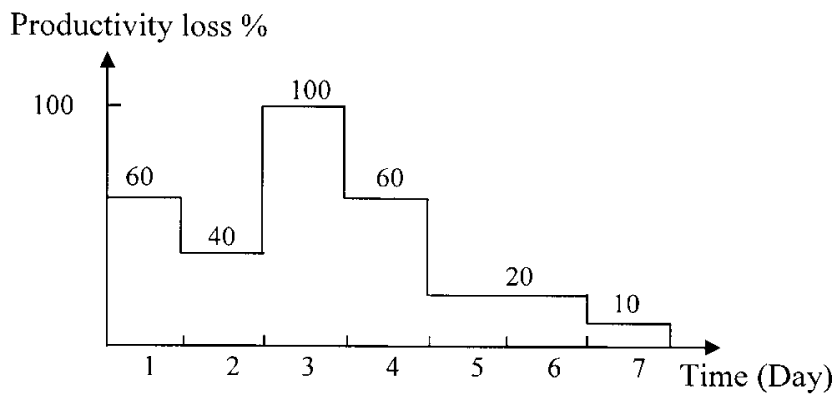

Fig. 5. Case example of productivity losses attributed to multiple rainfalls.

Equation (9):

$$
L_{i}= \begin{cases}L_{i D}+\Sigma L_{i j} & L_{i D}+\Sigma L_{i j} \leq 1 \\ 1 & L_{i D}+\Sigma L_{i j}>1\end{cases}
$$

where $L_{i D}$ is the direct productivity loss attributed to the rainfall on the $i$ th day and $\Sigma L_{i j}$ is the accumulation of subsequent productivity losses attributed to previous rainfalls on the $i$ th day.

\subsection{Schedule impact subjected to rain}

Once the productivity loss is determined as in the preceding section, the schedule impact for a specific activity can be calculated as in Equation (10). The $T_{R}$ is determined as the minimum items deemed necessary to ensure that the summation of "remaining productivity" reaches $T_{o}$. Restated, it is the duration deemed necessary to complete the activity by the remaining productivity under the impact of multiple rainfalls.

$$
\sum_{i=1}^{T_{R}}\left(1-L_{i}\right) \geq T_{o}
$$

where $T_{o}$ is the activity duration under the no-rain situation and $T_{R}$ is the activity duration subjected to the impact of rain.

For a case example (as Figure 5 depicts), assume that $T_{o}$ is equal to 3 days; then $T_{R}$ can be calculated as follows. At least six items are necessary for the summation to become equal 
to or greater than $T_{o}$. Therefore, the revised duration $T_{R}$ can be obtained as 6 days.

$$
\begin{array}{r}
\left(1-L_{1}\right)+\left(1-L_{2}\right)+\cdots+\left(1-L_{T R}\right) \geq 3 \\
0.4+0.6+0+0.4+0.8+0.8 \geq 3
\end{array}
$$

\section{SYSTEM STRUCTURE}

The daily data of precipitation for the past three decades (1967-1997) in 11 major areas and cities in Taiwan were accumulated to integrate with the analytical model for calculating the schedule impact of rain. In this study, the MsProject was adapted as the system mainframe to construct a computer-aided schedule forecasting system for construction projects subjected to the impact of rain. The Ms-Project is a readily available and useful software for project scheduling. Although some of the functional capabilities may not compete with other major scheduling tools such as P3 and OPENPLAN, Ms-Project has become increasingly popular due to its friendly interface, system application, and other advanced function features. The historical daily data of precipitation are developed in a database format and linked to the Ms-Project's input file. Other interfaces for importing data about the locations of construction sites and the starting dates of projects are programmed by Visual Basic to link with Ms-Project. All the functional capabilities of Ms-Project are still available for the system user.

In this computer-aided system, the user must first specify the location of the construction project as well as the project's starting date. Then the system is automatically linked with the related data on precipitation. A selection interface was build into the system for the user to select the year(s) of precipitation data for simulation. The user can select a specific year of high precipitation for pessimistic forecasting or the 30 sets of data for simulation. This system also contains the results of questionnaire surveys and expert reviews for default input that can be revised by the user for possible modification. A pull-down menu and interface are provided for the user to view and update the historical daily data on precipitation if expansion is necessary. Figure 6 depicts the system structure, and Figure 7 displays the calcualting flowchart.

\section{ILLUSTRATIVE EXAMPLE}

In this study, a typical real-life highway construction project was used to demonstrate the performance of this computeraided schedule forecasting system. This project is located in the Keelung area of north Taiwan. Table 3 lists the preliminary information of the activities in the network as well as the predecessors and the duration under no-rain basis.

Four different conditions were tested to examine the schedule impact of rain as well as the effectiveness of this system.

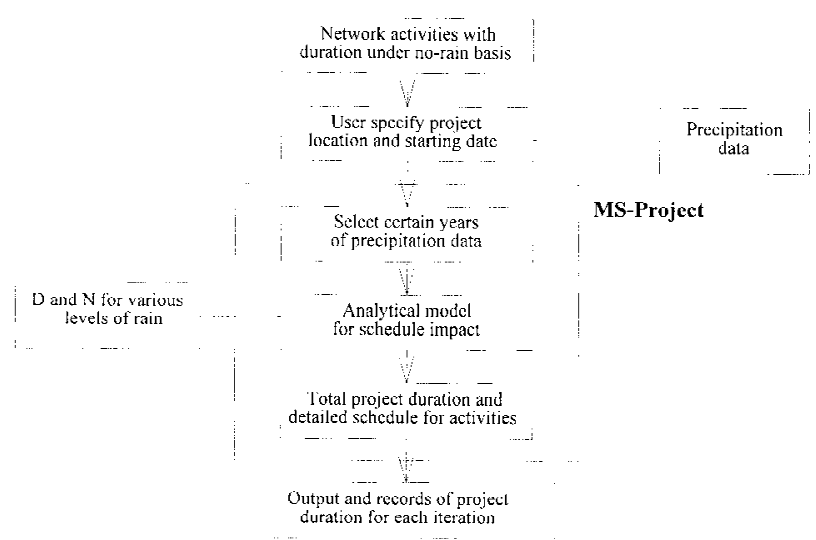

Fig. 6. System structure for the computer-aided forecasting system.

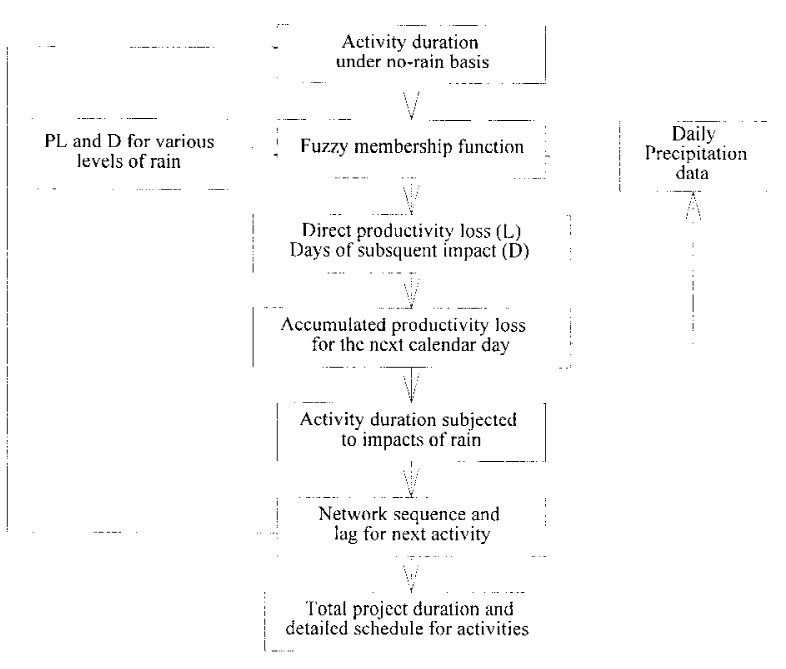

Fig. 7. Calculating flowchart for schedule impact of rain.

They are in the Kaoshiung area with the starting dates of January 1, 1997 and August 1, 1997 and in the Keelung area with the starting dates of January 1, 1997 and August 1, 1997, respectively. The Kaoshiung area is located in south Taiwan, in which the impact of rain is insignificant and the summer is the rainy season. Comparatively, the Keelung area is located in north Taiwan, in which the impact of rain is significant and the summer has less precipitation. Figure 8 presents the average monthly precipitation of each month in the Kaoshiung and Keelung areas for the past three decades. Although this system used the daily data on precipitation, the data in Figure 8 already imply a significant impact of total project duration. Notably, even though the project is constructed in the same Kaoshiung area, if the starting date is shifted from August 1 to January 1, the backfill and compacting activity may need to be done in the rainy season instead of during a slight-rain situation. In this case, the schedule im- 
Table 3

Preliminary information of highway construction example

\begin{tabular}{rlrc}
\hline & \multicolumn{1}{c}{ Activity } & No-rain duration & Predecessors and lag \\
\hline 1 & Site clearing & 135 & None \\
2 & $17+900-20+300$ excavation & 95 & $1 \mathrm{SS}+14 d^{*}$ \\
3 & $21+900-24+500$ excavation & 149 & 2 \\
4 & $17+900-20+300$ backfill & 110 & $2 \mathrm{SS}+14 d$ \\
5 & $21+900-24+500$ backfill & 124 & 4 \\
6 & Base-level aggregate & 18 & 5,3 \\
7 & $17+900-20+300$ base-level asphalt & 60 & 6 \\
8 & $21+900-24+500$ base-level asphalt & 66 & 7 \\
9 & $17+900-20+300$ compact graded asphalt & 59 & $7 \mathrm{SS}+7 d$ \\
10 & $21+900-24+500$ compact graded asphalt & 62 & $9,8 \mathrm{SS}+7 \mathrm{~d}$ \\
11 & Open-graded asphalt & 18 & 10 \\
\hline
\end{tabular}

* $1 \mathrm{SS}+14 \mathrm{~d}$ : start-to-start relationship with 14 days lag of activity 1 .

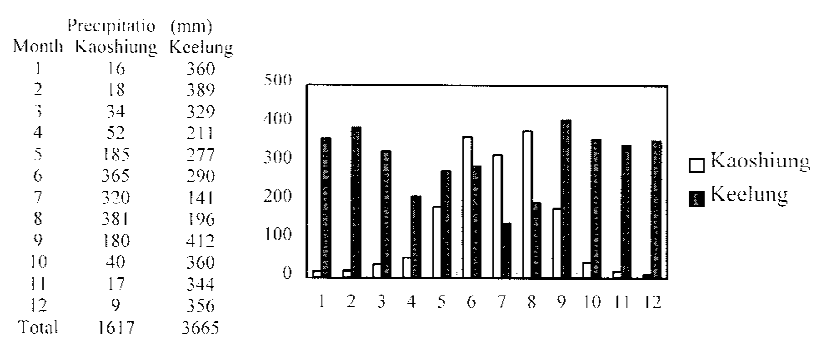

Fig. 8. Average monthly precipitation in Kaoshiung and Keelung (mm).

pact of rain is essential, resulting in a significantly extended duration.

Table 4 displays the project duration forecasting, as simulated by this schedule forecasting system for the preceding four conditions versus actual project duration. This real-life project was completed in September 1998. The actual total project duration was 912 days, which included a change order of 40 days' duration extension. Tables 5 and 6 list the detailed schedule for each project activity in the Kaoshiung and Keelung areas, respectively, with starting date on January 1 . The significant difference in total project duration reveals the importance of considering the schedule impact of rain. Table 7 compares the different activity durations in the Kaoshiung area with project starting dates of January 1 and August 1.

\section{DISSCUSSION AND SYSTEM VERIFICATION}

The schedule forecasting results in Tables 4 to 7 show essential differences and deserve close examination. The precipitation data in Figure 8 reveal that the total precipitation in the Keelung area is more twice that of the Kaoshiung area.
Meanwhile, for the same project to be constructed in different locations, the computer system estimates that the total duration in Keelung is approximately 1 year longer (892 versus 516 days) than in Kaoshiung. The fact that the precipitation in Kaoshiung is insignificant accounts for why the total duration in Kaoshiung is only about 3 months longer (516 versus 427 days) than the no-rain situation. Consider a situation in which the project manager or scheduler either neglects the productivity loss and subsequent impact of rain or is unfamiliar with the weather and distribution of rain in the Keelung area. Under such a circumstance, the experience-based judgment of precipitation impact on the project schedule may be underestimated. In a situation such as the illustrative example, a general duration estimate for this project in Keelung is 700 days. It was found by adding 6 months to the total duration in Kaoshiung so as to consider twice the amount of precipitation in Keelung. This estimate appears acceptable for some project managers and schedulers. However, the duration forecasting system developed in this study estimates an 892-day duration by adopting the daily precipitation data in Keelung. If the prediction result of the system is correct, then the underestimated experience judgment of project duration could cause a serious schedule delay. The cost for compressing the schedule and the enormous amount of delay penalty may directly contribute to project failure.

As in Table 4, the actual total project duration of this real-life project was 912 days. Subtracting the 40-day extension of the change order, it takes 872 days to complete this project. This result is quite close to the prediction of the proposed computer-aided system. On the contrary, the estimate (700 days) made by an experienced scheduler from the Kaoshiung area has been proved to be overoptimistic and unrealistic. The effectiveness and value of this system also have been demonstrated by several other highway construction projects. As a result, this proposed computer-aided system is highly appreciated by those experts and schedulers who assisted in this research. 
Table 4

Project duration forecasting versus actual total project duration

\begin{tabular}{lcccccc}
\hline $\begin{array}{l}\text { Location, } \\
\text { start date }\end{array}$ & No-rain & $\begin{array}{c}\text { Kaoshiung, } \\
\text { August 1 }\end{array}$ & $\begin{array}{c}\text { Kaoshiung, } \\
\text { January 1 }\end{array}$ & $\begin{array}{c}\text { Keelung, } \\
\text { August 1 }\end{array}$ & $\begin{array}{c}\text { Keelung, } \\
\text { January 1 }\end{array}$ & $\begin{array}{c}\text { Keelung, } \\
\text { 3/15/1996 }\end{array}$ \\
\hline $\begin{array}{c}\text { Project } \\
\text { duration } \\
(\text { days })\end{array}$ & 427 & 516 & 531 & 892 & 850 & 912 \\
\hline
\end{tabular}

Table 5

Detailed schedule for each activity in Kaoshiung

\begin{tabular}{rlccc}
\hline & \multicolumn{1}{c}{ Activity } & Duration & Start date & Finish date \\
\hline 1 & Site clearing & 148 & $1997 / 1 / 1$ & $1997 / 5 / 28$ \\
2 & $17+900-20+300$ excavation & 104 & $1997 / 1 / 15$ & $1997 / 4 / 28$ \\
3 & $21+900-24+500$ excavation & 208 & $1997 / 4 / 29$ & $1997 / 11 / 22$ \\
4 & $17+900-20+300$ backfill & 135 & $1997 / 1 / 29$ & $1997 / 6 / 12$ \\
5 & $21+900-24+500$ backfill & 172 & $1997 / 6 / 13$ & $1997 / 12 / 1$ \\
6 & Base-level aggregate & 18 & $1997 / 12 / 2$ & $1997 / 12 / 19$ \\
7 & $17+900-20+300$ base-level asphalt & 67 & $1997 / 12 / 20$ & $1998 / 2 / 24$ \\
8 & $21+900-24+500$ base-level asphalt & 79 & $1998 / 2 / 25$ & $1998 / 5 / 14$ \\
9 & $17+900-20+300$ compact graded asphalt & 66 & $1997 / 12 / 27$ & $1998 / 3 / 2$ \\
10 & $21+900-24+500$ compact graded asphalt & 75 & $1998 / 3 / 4$ & $1998 / 5 / 17$ \\
11 & Open-graded asphalt & 29 & $1998 / 5 / 18$ & $1998 / 6 / 15$ \\
& Total project duration in Kaoshiung & 531 & $1997 / 1 / 1$ & $1998 / 6 / 15$ \\
\hline
\end{tabular}

Table 6

Detailed schedule for each activity in Keelung

\begin{tabular}{clccc}
\hline & \multicolumn{1}{c}{ Activity } & Duration & Start date & Finish date \\
\hline 1 & Site clearing & 221 & $1997 / 1 / 1$ & $1997 / 8 / 9$ \\
2 & $17+900-20+300$ excavation & 188 & $1997 / 1 / 15$ & $1997 / 7 / 21$ \\
3 & $21+900-24+500$ excavation & 295 & $1997 / 7 / 22$ & $1998 / 5 / 12$ \\
4 & $17+900-20+300$ backfill & 216 & $1997 / 1 / 29$ & $1997 / 9 / 1$ \\
5 & $21+900-24+500$ backfill & 280 & $1997 / 9 / 2$ & $1998 / 6 / 8$ \\
6 & Base-level aggregate & 24 & $1998 / 6 / 9$ & $1998 / 7 / 2$ \\
7 & $17+900-20+300$ base-level asphalt & 113 & $1998 / 7 / 3$ & $1998 / 10 / 23$ \\
8 & $21+900-24+500$ base-level asphalt & 157 & $1998 / 10 / 24$ & $1999 / 3 / 29$ \\
9 & $17+900-20+300$ compact graded asphalt & 107 & $1998 / 7 / 10$ & $1998 / 10 / 24$ \\
10 & $21+900-24+500$ compact graded asphalt & 141 & $1998 / 10 / 31$ & $1999 / 3 / 20$ \\
11 & Open-graded asphalt & 41 & $1998 / 3 / 21$ & $1999 / 4 / 30$ \\
& Total project duration in Keelung & 850 & $1997 / 1 / 1$ & $1999 / 4 / 30$ \\
\hline
\end{tabular}

On the other hand, the detailed schedule for each activity, as presented in Tables 5 and 6 , also must be examined to focus management efforts on those activities significantly affected by the rain. According to the results, in this highway construction project, except the base-level aggregate and open-grade asphalt, the remaining activities are related to excavation, backfill, and compacting. Thus the impact of rain is essential, accounting for why the different amounts of precipitation cause enormous differences in total project duration (850 versus 531 days) for different project locations.
Finally, even in the same project location, different starting dates also may result in significant differences in project schedule and total duration. The estimated results in Table 7 display the impact. According to the precipitation data in Figure 8, May to September are the major rainy months in Kaoshiung. The ultimate differences in total project duration are attributed primarily to the schedule impact of rain on activities 3,5, and 7. Although the total duration difference in Table 7 is only 15 days, under a circumstance in which productivity is critical to rainy seasons, the different project 
Table 7

Comparison of activity duration in Kaoshiung with different starting dates

\begin{tabular}{rlrcr}
\hline \multicolumn{1}{c}{ Activity } & $\begin{array}{c}\text { No-rain } \\
\text { duration }\end{array}$ & $\begin{array}{c}\text { Start on } \\
\text { Jan. 1, 1997 }\end{array}$ & $\begin{array}{c}\text { Start on } \\
\text { Aug. 1, 1997 }\end{array}$ \\
\hline 1 & Site clearing & 135 & 148 & 156 \\
2 & $17+900-20+300$ excavation & 95 & 104 & 115 \\
3 & $21+900-24+500$ excavation & 149 & 208 & 165 \\
4 & $17+900-20+300$ backfill & 110 & 135 & 126 \\
5 & $21+900-24+500$ backfill & 124 & 172 & 141 \\
6 & Base-level aggregate & 18 & 18 & 27 \\
7 & $17+900-20+300$ base-level asphalt & 60 & 67 & 101 \\
8 & $21+900-24+500$ base-level asphalt & 66 & 79 & 72 \\
9 & $17+900-20+300$ compact graded asphalt & 59 & 66 & 96 \\
10 & $21+900-24+500$ compact graded asphalt & 62 & 75 & 67 \\
11 & Open-graded asphalt & 18 & 29 & 19 \\
& Total project duration in Kaoshiung & 427 & 531 & 516 \\
\hline
\end{tabular}

startings date may significantly impact the project schedule and total duration.

\section{CONCLUSIONS}

This study presents an analytical model to evaluate the productivity loss attributed to rain and precipitation. Based on the proposed model, a computer-aided system is developed for project duration forecasting subjected to the impact of rain. This duration forecasting system demonstrates practical application in the schedule planning process, particularly while considering the impact of rain. In addition, a typical highway construction project is used for testing the performance and effectiveness of the system. The real-life project duration is also compared with the forecasted result as well as with the judgment-based duration estimate. According to the comparisons, the proposed system can achieve more realistic and accurate results to help the scheduler in considering the impact of rain.

This study incorporates the concept of different levels of rain, the direct productivity loss attributed to different amounts of rain, the subsequent productivity impact of rain, and finally, the historical daily data of precipitation for project duration forecasting. The user is allowed to specify a certain year's precipitation data on which the simulation is based on. Although this study use the precipitation data for Taiwan to develop this computer-aided system, the overall methodology in developing this computer schedule forecasting system can be applied to other countries as long as historical data on precipitation are available.

\section{ACKNOWLEDGMENTS}

I would like to thank the National Science Council, Republic of China, for financially support this research under Contract No. NSC-87-2211-E-002-059.

\section{REFERENCES}

1. Adeli, H. \& Karim, A., Scheduling/cost optimization and neural dynamics model for construction, Journal of Construction Engineering and Management, ASCE, 123 (4) (1997), 450-8.

2. Ahuja, H. N. \& Nandakumar, V., Simulation model to forecast project completion time, Journal of Construction Engineering and Management, ASCE, 111 (4) (1985), 325-42.

3. Ayyub, B. M. \& Haldar, A., Project scheduling using fuzzy set concept, Journal of Construction Engineering and Management, ASCE, 110 (2) (1984), 189-204.

4. Benjamin, N. B. H. \& Greenwald, T. W., Stimulating effects of weather on construction, Journal of Construction Division, ASCE, 99 (1) (1973), 177-80.

5. Carr, R. I., Simulation of construction project duration, Journal of Construction Division, ASCE, 105 (2) (1979), 117-28.

6. Crandall, K. C., Probabilistic time scheduling, Journal of Construction Division, ASCE, 102 (3) (1976), 415-23.

7. Moder, J. J., Phillips, C. R. \& Davis, E. W., Project Management with CPM, PERT and Precedence Diagramming, Van Nostrand Reinhold, New York, 1983.

8. Moselhi, O., Gong, D. \& El-Rayes, K., Estimating weather impact on the duration of construction activities, Canadian Journal of Civil Engineering, 24 (3) (1997), 359-66.

9. Padilla, E. M. \& Carr, R. I., Resource strategies for dynamic project management, Journal of Construction Engineering and Management, ASCE, 117 (2) (1991), 279-93.

10. Smith, G. R. \& Hancher, D. E., Estimating precipitation impact for scheduling, Journal of Construction Engineering and Management, ASCE, 115 (4) (1989), 552-66.

11. Touran, A. \& Wiser, E. P., Monte Carlo technique with correlated random variables, Journal of Construction Engineering and Management, ASCE, 118 (2) (1992), 258-72. 